\title{
Teaching Research Writing to Chinese Graduate Students: A Guided Discovery Genre Approach
}

\author{
Hua Guo ${ }^{1}$ \\ ${ }^{1}$ College of Foreign Languages and Literatures, Fudan University, China \\ Correspondence: Hua Guo, College of Foreign Languages and Literatures, Fudan University, China. E-mail: \\ guohua@fudan.edu.cn
}

Received: August 30, 2021

Accepted: October 8, $2021 \quad$ Online Published: October 29, 2021

doi:10.5539/ijel.v11n6p112

URL: https://doi.org/10.5539/ijel.v11n6p112

\begin{abstract}
One of the biggest challenges graduate-level research writing instructors face is how to motivate students in large and multidisciplinary classes effectively. This article explores the influence of a guided inductive and discovery-based genre approach on improving students' knowledge of research writing. A questionnaire survey was conducted, and some of the students' written assignments were analyzed. The survey results show that the students were generally satisfied with this approach and affirmed its effectiveness in increasing their knowledge of the textual organization, format and documentation, and language style in research writing. Examining the students' written analysis of the move structure of abstracts indicates that this approach has enhanced the students' ability to identify moves and facilitated their acquisition of more appropriate genre knowledge. Further examination of the students' written reflections reveals a more in-depth understanding of their learning experience. Implications and directions for future research are discussed.
\end{abstract}

Keywords: research writing, graduate students, genre pedagogy

\section{Introduction}

Graduate-level research writing, according to Cheng (2018), refers to "scholarly writing" that graduate students "need to learn to engage in peer-responsive written communication about their research" (p. 1). Graduate students are a unique group of nascent scholars and learners of research writing, and though not well established in academia, they are acculturated into their disciplinary communities through research writing (Cheng, 2018). Compared to undergraduate students, graduate students are engaged in more varied and more sophisticated academic written communications. To win acceptance and recognition in their chosen fields, graduate students must demonstrate writing expertise in research genres like dissertations, theses, and journal articles that meet the expectations of the students' respective disciplinary communities. More importantly, English as the dominant medium of academic publication, graduate students outside English-speaking countries are increasingly expected to produce English research papers to earn their degrees and advance their careers. Graduate students in China, like their counterparts in other non-English speaking countries, are increasingly under pressure to publish in high-impact English-medium international journals before graduation (Cheng, 2018; Li \& Flowerdew, 2020). However, due to their unfamiliarity with the rhetorical practices in research writing and inadequate understanding of the disciplinary expectations underlying the textual features, graduate students may lack confidence in their ability to write and publish in English and are likely to experience severe anxiety.

Language teachers' instruction on research writing is essential to graduate students' publication success, especially in non-English speaking countries (Li \& Flowerdew, 2020). Despite the general consensus among theorists and practitioners in EAP writing that immersion-or-apprenticeship-based learning is beneficial and even crucial to developing graduate students' research writing ability, various published accounts of pedagogical practices in research writing have demonstrated that mere immersion is not enough, and classroom instruction can activate the students' ability and quickly improve their confidence in research writing (Belcher, 2006; Cheng, 2018). However, "the multidisciplinary mix of students in graduate-level research writing class" often poses a challenge for language teachers (Cheng, 2018, p. 24). Given that students are from a variety of disciplines that may not share research traditions and writing styles, language teachers, who are not necessarily well-acquainted with discipline-specific knowledge and skills across all fields of study, are likely to experience feelings of uncertainty (Norris \& Tardy, 2006). The possible inability of language teachers to provide more constructive 
instruction for multidisciplinary graduate students other than instruction on general language issues is likely to discourage students from being highly motivated to learn research writing in a way best suited to their discipline-specific epistemology, language proficiency, and writing experience.

To address this problem, researchers have explored the pedagogical interventions that could adequately meet multidisciplinary students' needs, and genre pedagogy is recognized as "one of the most theorized curricular orientations" in "addressing the very specialized discoursal needs of novice graduate writers" (Belcher, 2012, p. 136). While genre-based investigations into research writing, especially in the ESP tradition, have shown interdisciplinary and intradisciplinary differences in text organization and linguistic features (e.g., Harwood, 2006; Hu\&Cao,2011; Hyland, 2008; Lin \&Evans, 2012), some descriptions of discipline-based genre examples have been translated into pedagogical materials such as Swales and Feak (2012). Despite its value in enhancing students' research writing ability, the application of genre pedagogy in graduate-level research writing instruction is underrepresented in literature, except for a few case studies (e.g., Cheng, 2015; Kuteeva \& Negretti, 2016). Remarkably, these materials have not been effectively used in mainland China (Sun \& Wang, 2015). Therefore, this study draws on the findings from genre-based studies into research writing and explores the "guided inductive and discovery-based genre analysis" approach to teaching graduate students' research writing (Cheng, 2018, p. 88). This approach (abbreviated as guided discovery genre approach in this study), which combines the teacher's guided inductive analysis of genre samples and students' discovery-based analysis of genre samples, was primarily developed to nurture the genre-awareness of students in mixed-disciplines classes. Specifically, this study addresses the following research questions.

1) What overall impact does this approach have on students' learning of research writing?

2) What specific impact does this approach have on students' acquisition of genre knowledge in research writing?

\section{Method}

\subsection{Research Context}

The present study was conducted in a research-intensive university in mainland China and during a research writing course for graduate students. This course was designed to facilitate graduate students' writing English research articles for publication purposes and was offered on a weekly basis for a 16-week duration. Since this course involved multidisciplinary students, the teacher must create relevant and manageable tasks catering to the students' disciplinary needs. Following the guided discovery genre approach, students were first guided by the teacher to analyze the generic features of a sample journal article and they were then required to complete genre analysis tasks in their chosen field of study on an individual basis. Specifically, the teaching activities were centered on the writing of different sections of research papers. Heuristic questions were designed to develop student's abilities to conduct a multilayered text analysis of each section and detect the rhetorical purposes, textual organization and linguistic patterns typical of one specific section in the disciplinary and cultural context. Below are the activities listed in sequence.

1) Each student is required to create a collection of 5-8 sample papers from reputable English-journals in their respective disciplines; 2) Students draft a particular section based on their prior knowledge and experience; 3 ) The teacher demonstrates to students how to conduct a genre analysis of this particular section; 4) Students conduct a genre analysis of the corresponding section in their self-selected sample paper by responding to the teacher's questions; 4) Building on relevant studies and the teacher feedback, students update their results of genre analysis; 5) The teacher and students discuss and decide the evaluation criteria for the writing of this section; 6) Students improve on their writing of this particular section with respect to its rhetorical purposes, textual organization, and linguistic features and state the reasons for revisions; 7) Peer review, and teacher feedback; 8) Students revise this section following peer feedback and teacher feedback and submit their final version. To illustrate our activities, those designed for the writing of abstracts are shown in Table 1. 
Table 1. Teaching arrangements for abstract writing

\begin{tabular}{lll}
\hline Step & Topic & Time \\
\hline $\mathbf{1}$ & Students draft a 200-word abstract on their self-selected research & In class \\
$\mathbf{2}$ & Teacher guides the students to analyze the communicative purposes, move structure, and & In class \\
& linguistic features of a sample abstract & After class \\
$\mathbf{3}$ & Students independently analyze abstracts in their respective disciplines & After class \\
$\mathbf{4}$ & Students revise their abstracts and state reasons for revisions & In \& After class \\
$\mathbf{5}$ & Teacher provide feedback on students' abstracts. & After class \\
$\mathbf{6}$ & Students further revise their abstracts and submit the final version & \\
\hline
\end{tabular}

Through this series of activities, the students and the teacher have reached a consensus upon the major aspects of the writing of research articles, namely, rhetorical purposes, textual organization, and linguistic features. The students are thus transformed from passive learners in a writing class to active learners and writers. Genre analysis tasks and questions for genre analysis are exemplified in Table 2. Commonly used words and phrases in moves of research article abstracts generated from genre analysis tasks are illustrated in Table 3.

Table 2. An example of genre analysis tasks (adapted from Cheng, 2018, p. 91)

Focus on the abstract of two of your sample papers, and answer the following questions.

1) What are the moves that you have noticed in this section of the research paper? Use concrete action verbs to describe these moves (e.g., argue for).

2) Do you feel that these moves are logically connected? If not, why? If yes, could you explain in detail how these moves are logically connected?

3) Are these moves necessary? Should other moves have be added? Or should some moves have been taken out? Why?

4) What are the words, phrases and sentence patterns that have been used to perform each of the moves that you have identified?

5) What is the overall communicative purpose of this section of the research paper?

Table 3. Commonly used words/phrases in moves of research article abstracts

\begin{tabular}{ll}
\hline Move & Commonly used words/phrases \\
\hline Background & $\ldots$ is considered a promising (material/technique)/...is largely unknown \\
Purpose & (Here) we investigated/examined.../We propose/analyze.../This paper argues that... \\
Methods & (Questionnaires) were distributed/... was investigated using (analysis) \\
Results & Results show/reveal/indicate/suggest that.../We show/find that... \\
Conclusion & The conclusion is that.../We conclude that... \\
\hline
\end{tabular}

\subsection{Data Collection and Analysis}

The participants in this study were students from three natural classes, and came from various disciplines, including humanities, social sciences, science and engineering. These students were all first-year graduate students and had not taken any course or systematic training on research writing. They were requested to respond to a questionnaire survey designed to estimate their overall reception of this course and identify the essential benefits they had obtained regarding research writing. The questionnaire was designed following the end-of-semester common practice of this course with reference to evaluative statements in Cargill et al. (2012). Given the focus of this course on journal articles of all research genres like dissertations, theses, and research proposals, we took abstracts, an indispensable component of journal articles and one of the most studied part-genres, as an example to further examine the effect of the course on increasing students' genre knowledge of research writing. Three datasets were used to investigate students' knowledge about the move structure of abstracts. 1) the moves students believed an abstract should include; 2) the moves in the abstracts they produced before the instruction; and 3) the moves they recognize abstracts should comprise after the instruction. In addition, we also examined students' written reflections concerning the writing of abstracts to understand their learning experience.

\section{Results and Discussion}

Our questionnaire survey at the end of the course indicates the positive impact of the guided discovery genre approach on students' learning of research writing. A total of 88 valid questionnaires were collected. Of all the respondents, 47 were male students, and 41 were female students. Seventy-four of them were science and engineering students, and 14 were social science and humanities students. The questionnaire results showed that 
$91.2 \%$ of the students were "very satisfied" or "somewhat satisfied" with the course, suggesting the students' general satisfaction with the pedagogical practice. Regarding the teaching mode, $66.1 \%$ of the students preferred workshops compared to the support rate of $31.4 \%$ for lectures. For the specific teaching procedures, writing tasks, group analysis tasks, and individual analysis tasks enjoy the highest level of popularity among students, $63.5 \%$, $62.3 \%$, and $59.0 \%$, respectively, as contrasts with much lower support rate for peer assessment $(0.38 \%)$, self-assessment $(0.18 \%)$, and individual tutorials $(0.17 \%)$. Students' favorable opinion of genre analysis tasks fully reflects their recognition of the guided discovery genre approach.

The survey results also showed that at least $68.9 \%$ of the students believed that the course effectively improved their understanding of various aspects of research writing, including textual organization, language style, and format and documentation. Notably, $80.9 \%$ of the students affirmed the course's contribution to their mastery of the research paper's textual organization, which indicates that the students might have had very vague or limited knowledge about the macro-structure of research writing before they took the course. Their increased awareness of the paper's textual organization can be attributed to the series of genre analysis tasks of different sections of the research paper. As revealed by the students' comments concerning the benefits they had obtained from the course, the genre analysis tasks offered the students the chance to reconsider English research papers' overall structure and writing strategy and helped prepare their manuscripts ready for submission. While this course proved beneficial to students' acquisition of knowledge and skills related to research writing, most students believed that the teaching activities were also useful in improving their self-learning ability (92.3\%), critical thinking ability (86.9\%), and innovative ability $(74.9 \%)$. Therefore, our approach to research writing has positive effects on students' other research-related skills.

Specifically, the writing of abstracts was taken as an example to examine the specific effects of the guided discovery approach on students' research writing. The choice of abstract writing as the focus of our present study is motivated by the essential functions of abstracts and the difficulties involved in producing one. Abstracts are long-recognized as stand-alone "mini texts," giving a summary of the article, "screening devices," helping readers to decide whether to pay further attention to the whole article and "previews," offering a roadmap for those intending to read the entire article (Huckin, 2001, p. 93). Additionally, the word limit usually imposed on abstracts makes the writing of abstracts a demanding task, and even expert and well-published writers need to constantly rewrite to produce a satisfying version that could summarize their articles with maximum efficiency and clarity (Swales \& Feak, 2009). Therefore, novice writers' learning to write an abstract is worth close examination.

Much work has investigated the rhetorical moves of abstracts in various languages and disciplines and has generally agreed on a five-move structure, which typically consists of background, purpose, methods, results, and conclusion (Swales \& Feak, 2009, p. 9) and serves as a most accessible template for research writers to organize their abstracts. In the present study, we conducted a comparative analysis between the move structure of abstracts students recognized before the instruction and the moves they believed abstracts typically comprise after the instruction. We also drew a comparison between the move structure of abstracts the students recognized and the structure they used in composing abstracts before they took the class. Our results revealed that students generally recognized more moves in an abstract after the instruction than the moves they thought there should be This finding indicates that most students acknowledged the need to produce a "standard" abstract that should include almost all the moves identified, confirming Hyland's (2004) argument that research writers increasingly preferred a more sophisticated move structure in the effort to increase the chances of the article being accepted by the target journal and read by a broader readership.

Our results also showed that students' gains on abstract writing were not equally distributed among all the moves. Specifically, the "results" move seemed universal in abstracts written before the class and those produced after the class, thus indicating students' familiarity with this move and their awareness of the necessity to include this move in abstracts even before they took the class. The students' solid knowledge about the "results" move was further confirmed by the consistency in the occurrence of the "results" move between the move structure they knew and the one they used in their writing. Meanwhile, a noticeable increase occurred in the "purpose" move. While they seemed to conflate the "purpose" move with the "methods" move before the class, the students tended to distinguish between the two moves after the class, which indicates their ability to identify the "purpose" move and establish it as a separate move. Considering that the purpose move is almost obligatory in the move structure, this move's increasing presence in the abstracts the students produced after the class suggests that the class activities have enabled the students to acquire a more appropriate genre knowledge about abstract writing.

Noteworthy is the discrepancy between the student's declarative knowledge and procedural knowledge about abstract writing. According to Anderson and Lebiere (2014), declarative knowledge refers to knowledge of 
"things we are aware we know and can usually describe to others," whereas procedural knowledge is the knowledge that we "display in our behavior but that we are not conscious of" (p. 5). In this study, the moves that the students believed should constitute an abstract was not consistent with the moves they were not necessarily aware of but could use to compose one. Specifically, they seemed to recognize fewer moves than those in the abstract they produced. This finding pertains to all the moves under investigation except the conclusion move and may highlight the students' implicit knowledge about writing an abstract that they could not articulate. In this respect, our teaching activities effectively transformed their implicit genre knowledge about abstracts into explicit knowledge. Furthermore, the students' written reflections on the abstract's communicative purposes, text structure, and linguistic features were analyzed. The major impacts of the guided discovery genre approach can be summarized as follows.

1) Misconceptions clarified. Despite their experience of reading and writing research papers, graduate students' knowledge of abstract writing generally remained intuitive and was sometimes inappropriate. As previously discussed, students' declarative knowledge about abstract writing could contradict their procedural knowledge about abstract writing. Their inadequate knowledge about research writing is likely to impact their writing competence negatively. Following the teacher's explicit genre analysis of abstracts in class, the students' discovery-based genre analysis tasks and their experience of writing and revising abstracts prompt them to reconsider an abstract's organization and functions.

"I used to believe that the abstract, the last paragraph of the introduction, and the conclusion are roughly the same in terms of structure and content. That explains why I thought I merely needed to include methods and results in my abstract. Now I know an abstract is a mini research paper." (Student 3(S3))

"The abstract primarily differs from the introduction in that the introduction does not necessarily include the experimental results and the discussion." (S12)

"In the results section of an abstract, we do not need to list all the experimental results, and instead, a selection of representative or innovative results should be presented." (S20)

2) Reader awareness enhanced. While the traditional teacher-centered instruction usually emphasizes students' language proficiency and teachers' evaluation in research writing, our approach offered the students the opportunities to experience the interaction between the author, the reader, and the text during their genre analysis tasks. As they came to perceive research writing as a process of social communication, the students developed the ability to consider the reader's needs and expectations.

"Now I realize that the purpose of an abstract is to enable the reader to acquire the necessary information about a research paper without reading the whole paper." (S16)

"Abstract is the first thing accessed by the reader whenever they start reading a research paper, and in this regard, the abstract is a 'façade' of the paper." (S20)

"The abstract should not be too short. Otherwise, the reader is likely to obtain too limited information about the research paper. On the other hand, the abstract should not be too long, and plain sentences are preferred. Long sentences would cost the reader a large amount of time and thus reduce the reading efficiency". (S31)

3) Rhetorical awareness developed. According to genre pedagogy, students are expected to follow an organizational pattern that best realizes the communicative purposes of a genre. An abstract, being one of the first components accessed of an article by readers and reviewers, will influence how the rest of the text is received. Knowing that an abstract summarizes the research, particularly the objective and the main findings, students would be more likely to learn its textual organization. Our genre analysis tasks encouraged students to explore the communicative purposes and the move structure of abstracts, and consequently, the students demonstrated a heightened awareness of the generic structure of abstracts.

"An abstract is to summarize the paper in clear and concise language, and it consists of four parts, that is, purpose, methods, results, and conclusion". (S3)

"By examining the abstracts of sample research papers, I learn the major components of abstracts, that is, research background, research question, research results and recommendations for future research." (S13)

"I realize that I did not include research background and research objectives in my earlier draft of the abstract and went down to writing the materials and methods in the first place." (S15)

4) Linguistic competence improved. In a teacher-centered writing class, the teacher explains typical sentence structures and linguistic expressions, and the students are required to write on the model of sample texts. In comparison, our approach encouraged students to compare the differences between their draft abstracts and those 
of expert writers and gradually developed their ability to read and write scientific English with "a nuanced understanding of the language of the specialty" (Bazerman et al., 2012, p. 236). Further informed by literature on abstract writing, the students were motivated to investigate the characteristics of high-quality abstracts and acquired a solid knowledge about aspects like language style, sentence patterns, wording, and verb tenses.

"The language should be straightforward and not too literary." (S13)

"More simple sentences should be used to highlight key points." (S16)

"Now I am aware that abstracts should use more academic vocabulary and avoid colloquialism." (S20)

"We can use more adverbs to produce a more compact structure." (S23)

"Active voice is preferred over passive voice." (S35)

"For background information, we should use the simple present tense to describe the well-received facts that remain truth across time, and present perfect tense is preferred in descriptions of general trends." (S47)

"Simple past tense is often used to describe the experimental procedure or methods; simple present tense could be used if the experimental results are generally valid." (S51)

"When discussing the implications and prospects, we could use modal verbs to indicate probability." (S63)

Taken together, the guided discovery approach has guided students to investigate the rhetorical purposes, textual organization, and linguistic features of each section of the research paper and helped acculturate the students to their respective academic communities by raising their rhetorical awareness in argumentation before a discipline-specific audience. In addition to a general knowledge of research paper writing norms and techniques, students have become acquainted with the more specific knowledge about the writing process and textual features of research papers in their chosen fields of study. Therefore, these students' understanding of research writing is deepened, and their writing competence is improved.

\section{Conclusion}

This exploratory study demonstrates that the guided inductive and discovery-based approach to research writing instruction can enhance students' understanding of the rhetorical and linguistic features of research writing and improve their academic reading and writing skills. Students were particularly benefited from the lexico-grammatical features being taught in relation to their rhetorical functions (Cargill et al., 2018). Using this approach, the teacher can actively involve the students in the learning process, and by '[raising] students' awareness of the potential variation of the features in texts from different disciplines" (Li \& Flowerdew, 2020, p. 33), can further empower them to participate in their discipline-specific scholarly communications confidently. Despite the general effectiveness of this approach, there might be some limitations. Given the size of classes and variety of disciplines involved, our class activities tend to focus on communicative purposes, rhetorical structures, and linguistic features that are common to research paper writing across disciplines and do not give adequate attention to an in-depth discussion of discipline-specific wording and sentence patterns in both published and student papers. Also noteworthy is that students vary in their content knowledge and research writing experience. While our approach may not appear immediately effective in enhancing some students' research writing competence, they may be discouraged from participating in in-class and after-class activities. For future pedagogical practice, we will still utilize students' self-built collection of research papers in their respective disciplines and pay more attention to the close integration of genre analysis tasks and writing practices. Specifically, genre analysis activities can focus on students' papers and published papers, with more frequent comparative analyses drawn between these two types of writing, which can heighten students' awareness of discipline-specific features in research writing. Furthermore, we could explore the "buddy system" for this course by pairing more experienced writers and beginning writers and create tasks that better suit students' writing proficiency and writing needs.

\section{References}

Anderson, J. R., \& Lebiere, C. (2014). The atomic components of thought. New York: Psychology Press. https://doi.org/10.4324/9781315805696

Belcher, D. (2006). English for specific purposes: Teaching for perceived needs and imagined future in worlds of work, study and everyday life. TESOL Quarterly, 40, 133-156. https://doi.org/10.2307/40264514

Belcher, D. (2012). Considering what we know and need to know about second language writing. Applied Linguistics Review, 3, 131-150. https://doi.org/10.1515/applirev-2012-0006

Cargill, M., Gao, X., Wang, X., \& O’Connor, P. (2018). Preparing Chinese graduate students of science facing an 
international publication requirement for graduation: Adapting an intensive workshop approach for early-candidature use. English for Specific Purposes, 52, 13-26. https://doi.org/10.1016/j.esp.2018.05.002

Cargill, M., O'Connor, P., \& Li, Y. (2012). Educating Chinese scientists to write for international journals: Addressing the divide between science and technology education and English language teaching. English for Specific Purposes, 31, 60-69. https://doi.org/10.1016/j.esp.2011.05.003

Cheng, A. (2015). Genre analysis as a pre-instructional, instructional, and teacher development framework. Journal of English for Academic Purposes, 19, 125-136. https://doi.org/10.1016/j.jeap.2015.04.00

Cheng, A. (2018). Genre and graduate level research writing. Ann Arbor: University of Michigan Press. https://doi.org/10.3998/mpub.9558175

Hu, G., \& Cao, F. (2011). Hedging and boosting in abstracts of applied linguistics articles: A comparative study of English- and Chinese-medium journals. Journal of Pragmatics, 43, 2795-2809. https://doi.org/10.1016/j.pragma.2011.04.007

Huckin, T. (2001). Abstracting from abstracts. In M. Hewings (Ed.), Academic writing in context: Implications and applications (pp. 93-103). London: Continuum.

Hyland, K. (2004). Disciplinary discourses: Social interactions in academic writing. Ann Arbor: University of Michigan Press.

Hyland, K. (2008). As can be seen: Lexical bundles and disciplinary variation. English for Specific Purposes, 27,1, 4-21. https://doi.org/10.1016/j.esp.2007.06.001

Kuteeva, M., \& Negretti, R. (2016). Graduate students' genre knowledge and perceived disciplinary practices: Creating a research space across disciplines. English for Specific Purposes, 41, 36-49. https://doi.org/10.1016/j.esp.2015.08.00

Li, Y., \& Flowerdew, J. (2020). Teaching English for research publication purposes (ERPP): A review of language teachers' pedagogical initiatives. English for Specific Purposes, 59, 29-41. https://doi.org/10.1016/j.esp.2020.03.002

Lin, L., \&Evans, S. (2012). Structural patterns in empirical research articles: A cross-disciplinary study. English for Specific Purposes, 31, 3, 150-160. https://doi.org/10.1016/j.esp.2011.10.002

Sun, Y., \& Wang, J. (2015). Retrospect and reflections: Genre pedagogy on second language writing. Journal of PLA University of Foreign Languages, 1, 44-50.

Swales, J. (1990). Genre analysis. Cambridge, UK: Cambridge University Press.

Swales, J., \& Feak, C. (2009). Abstracts and the Writing of Abstracts. Ann Arbor: University of Michigan Press. https://doi.org/10.3998/mpub.309332

\section{Appendix A}

\section{End-of-Semester Questionnaire for the "Research Writing for Graduate Students" Course}

In what areas do you think this course has improved your abilities? (Questions No. 1-4)

1. This course has improved your self-learning ability.

$\square$ Strongly agree $\square$ Somewhat agree $\square$ Neutral $\square$ Somewhat disagree $\square$ Strongly disagree

2. This course has improved your critical thinking ability.

$\square$ Strongly agree $\square$ Somewhat agree $\quad \square$ Neutral $\square$ Somewhat disagree $\square$ Strongly disagree

3. This course has improved your innovative ability.

$\square$ Strongly agree $\square$ Somewhat agree $\quad \square$ Neutral $\square$ Somewhat disagree $\square$ Strongly disagree

4. This course has improved your collaboration skills.

$\square$ Strongly agree $\square$ Somewhat agree $\quad \square$ Neutral $\quad \square$ Somewhat disagree $\square$ Strongly disagree

5. Which of the following teaching modes do you think is appropriate for this course?

$\square$ Lectures $\square$ Workshops $\square$ Seminars

6. Which of the following teaching procedures do you think is appropriate for this course?

andividual genre analysis tasks 
口Group genre analysis tasks

$\square$ Writing tasks

口Individual tutorials

口Self-assessment

$\square$ Peer assessment

7. In which of the following areas do you think the course has improved your understanding of research writing?

$\square$ Format and documentation

口Textual organization

口Language style

$\square$ Writing process

8. In general, were you satisfied with the course "Research Writing for Graduate Students"?

口Very satisfied $\square$ Somewhat satisfied $\square$ Neutral $\square$ Somewhat dissatisfied $\square$ Very dissatisfied

9. What would you suggest to improve the course "Research Writing for Graduate Students"? (Open-ended question)

Personal Information

1. Gender

$\square$ Male $\square$ Female

2. Subject category

$\square$ Humanities $\quad \square$ Social sciences $\quad \square$ Science \&engineering

3. Have you ever taken any course or formal training on research writing?

$\square$ Yes $\square$ No

\section{Copyrights}

Copyright for this article is retained by the author, with first publication rights granted to the journal.

This is an open-access article distributed under the terms and conditions of the Creative Commons Attribution license (http://creativecommons.org/licenses/by/4.0/). 